\title{
A NEW MERGED SEGMENTATION TECHNIQUE USED FOR X-RAY CHEST IMAGES
}

Balasubramani Perumal

Department of Electronics and Communication Engineering, Kalasalingam Academy of Research and Education, Krishnankoil, Virudhunagar (Dt), (India).

E-mail: palanimet@gmail.com ORCID: https://orcid.org/0000-0003-4408-9396

Emil Molayil Paul

Department of Electronics and Communication Engineering, Kalasalingam Academy of Research and Education, Krishnankoil, Virudhunagar (Dt), (India). E-mail:emilmpaul@gmail.com ORCID: https://orcid.org/0000-0003-0563-4240

\section{Citación sugerida:}

Perumal, B., y Paul, E. M. (2021). A new merged segmentation technique used for X-ray chest images. 3C Tecnología. Glosas de innovación aplicadas a la pyme, Edición Especial, (noviembre, 2021), 41 1-429. https:/ / doi.org/10.17993/3ctecno.2021.specialissue8.411-429 


\section{ABSTRACT}

Image processing techniques of a chest X-ray image includes noise removal followed by segmentation, feature extraction to locate regions and classification. The chest image appears differently when viewed from different angles or under different lightings. Diagnosing TB stays a challenge. The customary medical specialty, even so count, variety ways, they are gradual and frequently unreliable. In ancient poster anterior chest radiographs, several clinical and diagnostic functions build use of computationally designed algorithms that assist in scientific diagnostic analysis by victimization acquisition of pictures. The Digital image may be a necessary medium for analyzing, annotating, patient's demographics coverage in screening of $\mathrm{TB}$ via chest radiography. This paper deals with the essential segmentation methods of TB. In our methodology, this disease can be fastly and accurately identifiable by the merge segmentation methods of $\mathrm{K}$ means with Marker-based Watershed segmentation which has highest precision and recall values when compared to the several other segmentation methods which is been is discussed. More than 80 chest Xray images output for recall and precision is discussed here.

\section{KEYWORDS}

Watershed Segmentation, Marker-Based Watershed Segmentation, Otsu, K means, Gamma correction. 


\section{INTRODUCTION}

The chest X-ray films gives certain vital information about the patients. However, the researchers are been encouraged to develop computer algorithms to assist the radiologist in diagnosis process. Automatic segmentation is one of the first steps of such computer-aided systems. Medical imaging technological know-how could be facts managing an integrated system designed for the screening of T.B. patients. The screening technique is extended with the help of creating the reviewing procedure faster via reducing eye fatigue. In this paper we tend to discuss, regarding the varied automatic approaches for sleuthing the TB. Here numerous techniques are tailored for preprocessing, segmentation techniques. Our work combines the algorithm of marker-based watershed method along with the combination of normalization of the input image, gamma correction and k-means clustering. This enhances the ROI of the segmented portion. Here a comparison between various segmentation methods is performed depending on the precision and recall concepts.

\section{MATERIALS AND METHODS}

Screening is widely used for detection of tuberculosis. It's hard for a radiologist to interpret the disease. It's viable to improve this task through the use of CAD system (Raviglione \& Sulis, 2016). The first paper mainly deals with the necessity of the computerized method for the tuberculosis detection along with the various segmentations used. The pros and cons for each segmentation method is described here. The need for segmentation and how is it useful for x-ray chest image is referred here.

This paper depicts a voyage of the segmentation methods (Kumar et al., 2018; Karargyris, Antani, \& Thoma, 2011; Guendel et al., 2019). In TB screening, the segmentation part paves an important role. This paper deals with the involvement of marker-based watershed segmentation, which fairly well works than distance transform watershed transforms. Due to the few disadvantages in watershed segmentation, the chest radiographs are well segmented using marker-based watershed segmentation (Lu, Wang, \& Zhang, 2017; Zhang et al., 2013; Guendel et al., 2019).

The image segmentation using Otsu and $\mathrm{K}$ means is well explained in the paper. Depending upon the threshold value the classification for foreground and background is being done. 
$\mathrm{K}$ means clustering method goes in the circle of vector quantization, forms cluster of $\mathrm{k}$ in $\mathrm{n}$ mining region (Kasu \& Saravanan, 2019). The region growing method of chest segmentation is described in Kiran et al. (2019). The normalization of the x-ray input chest image is made due to the poor contrast or due to glare (Guendel et al., 2019; Vidya et al., 2019; Hoffman, Kothari, \& Wang, 2014). Then gamma correction is done as a luminance correction (Chen \& Ramli, 2003; Deivalakshmi, Saha, \& Pandeeswari, 2017).

The ROI is determined by merging the result of $\mathrm{K}$ means and watershed segmentation (Kasu \& Saravanan, 2019; Jeyavathana, Balasubramanian, \& Pandian, 2017; Betsy \& Nizar, 2017). Thus, by calculating the precision and recall of every segmentation mentioned in this paper and a total analysis of segmentation of all about 80 images are made.

\subsection{WATERSHED SEGMENTATION}

Automatic investigation of TB microorganism algorithms has conjointly been tested to be less time, less human error and less man-power. The Watershed transformation is a powerful tool for image segmentation, it uses the region-based approach. Here the concept of an image gradient came. It is a directional change in the intensity or color in of an X-ray chest image. It is been used to extract information from images. The approach consists of analyzing a picture, with the color thresholding segmentation before greyscale color. The excellence of the grayscale image has been increased, and binarization is performed. Here, we perform an experiment for calculating the precision and recall of around 80 chest $\mathrm{X}$-Ray images using watershed segmentation. The main disadvantage of this method is over segmentation. However, this can be reduced using internal and external markers. The original input lung image and the watershed segmented image is shown.

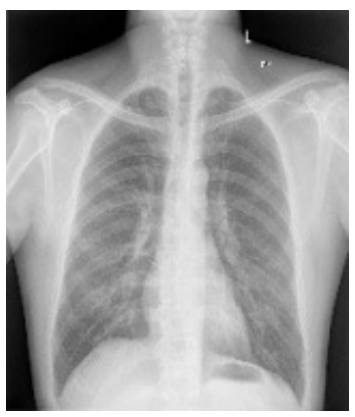

Figure 1. a) Input original image, b) Watershed image.

Source: own elaboration. 


\subsection{MARKER-BASED WATERSHED SEGMENTATION}

In Watershed Segmentation, two methods are involved. The first methodology quickly makes use of Watershed Segmentation on the image, to boot known as Watershed Distance transform Segmentation methodology. The second methodology, Marker-based Watershed Segmentation, which overcomes the over segmentation problem of the first method, limits the variability of regions through exploitation the inside markers to specify the ROI (Kasu \& Saravanan, 2019).

Unfortunately, the real watershed transform corresponds to a minimum of the gradient that is produced by small variations, due to noise. This leads to the over segmentation problem, which yields inaccurate results. The disadvantage of this over segmentation can be overcome by marking the patterns on the lung region of the x-ray image to be segmented. It should be performed before the watershed transformation of the gradient, which is been effectively reduced by using marker-based watershed segmentation.

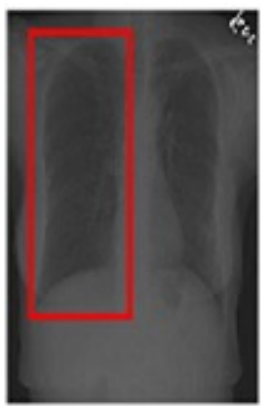

WUNG REGION

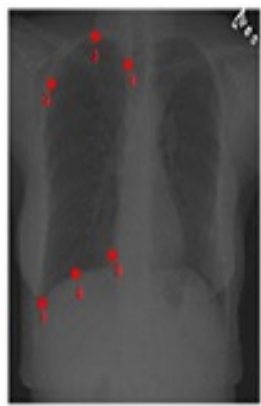

PORTION FOR SEGMENTATION

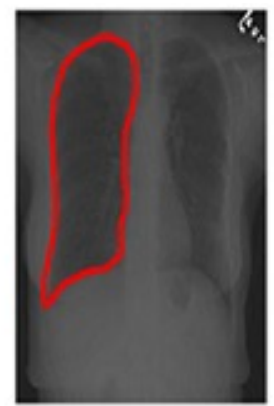

ROI

MLARKER BASED WATERSHED SEGMIENTATION (LUNG X-RAY IMAGE)

Figure 2. Marker-Based Segmentation.

Source: own elaboration.

\subsection{OTSU SEGMENTATION}

This Otsu segmentation automatically performs clustering-based segmentation. It converts gray level image into binary image. It accounts for foreground and background pixels. The main drawback of this segmentation is that if the variance of both the background and image 
remains high, the additive noises may disrupt the image clarity. The Otsu Segmentation is very much limited to low size object, with small mean difference and variance.

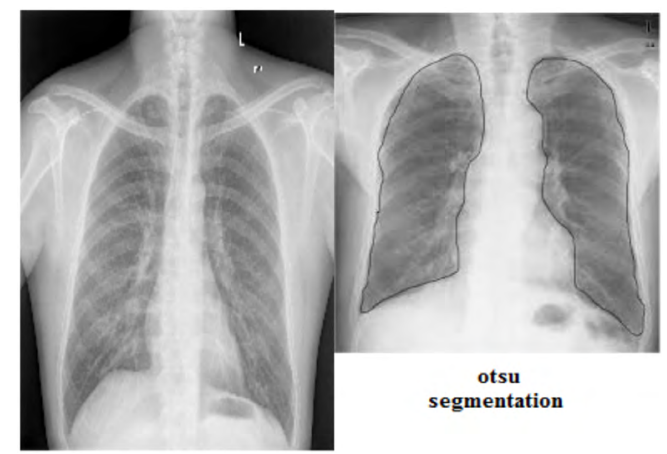

Figure 3. a) Input original image, b) Otsu Segmented Image.

Source: own elaboration.

\subsection{REGION GROWING SEGMENTATION}

The main goal of segmentation is to partition the X-ray chest images into suitable regions. It firstly, goes through the neighboring pixels of initial seed points, then determines whether the neighboring X-ray pixels should be added to the region. The iteration process proceeds next. The main disadvantages of this region growing includes:

1) Proper identification of the seed points.

2) Needs more information of the image.

3) The pixels with similar threshold value regions will be considered as same regions.

4) It is computationally expensive and more sensitive to noise.

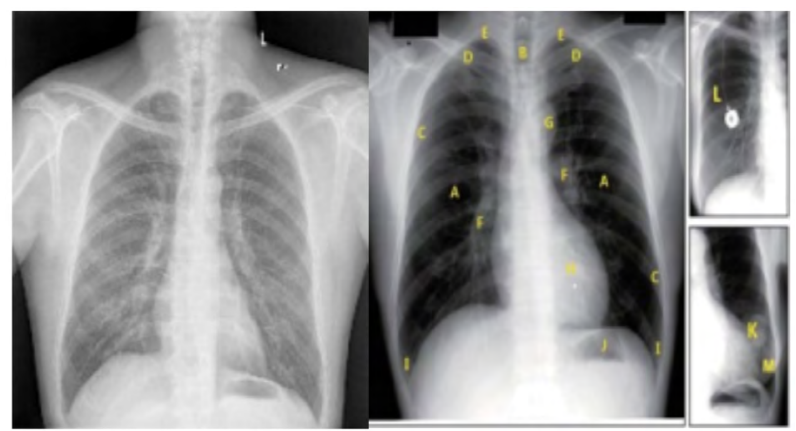

Figure 4. a) Input original image, b) Segmented Image.

Source: own elaboration. 


\subsection{K MEANS CLUSTERING}

It is a vector quantization method. It divides the $\mathrm{n}$ observations or pixel elements into $\mathrm{k}$ clusters. Here, the observation belongs to the cluster with meaningful value of mean. An observation for the pixel values of the input image and the $\mathrm{K}$ means clustering is depicted as graph shown below.

\section{Input Image $\mathbf{K}$ mean \\ Clustering}

Figure 5. a) Input original image, b) Segmented Image.

Source: own elaboration.

Green colour for cluster 1, rose colour for cluster 2, and yellow colour for cluster 3.

Here value of $\mathrm{K}=3$ is made. The first 2 values for $\mathrm{k}$ are for the left and right lungs and third value is for the background. It can be applied to larger data sets too. It uses an iterative technique.
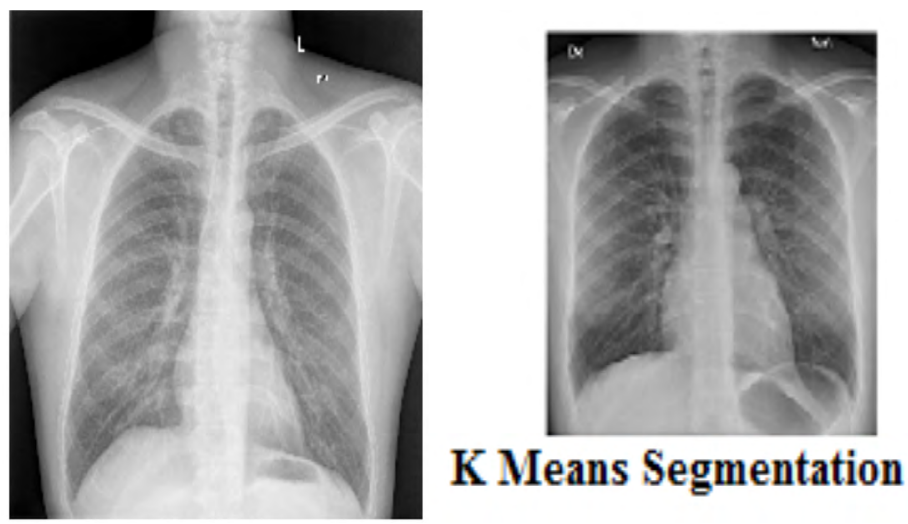

Figure 6. a) Input original image, b) K Means Image.

Source: own elaboration. 


\section{PROPOSED METHOD}

Our planned system contains the preprocessing followed by segmentation, feature extraction strategies, trained information sets and also the classifier. The preprocessing technique includes median, wiener and morphological filters (Top hat and bot hat filters). The median filters out the salt and pepper noises, but once the impulse noise is larger than $4 \%$, it filters out the helpful data within the chest pictures. It will bring an improbable loss in sleuthing the TB. Therefore, the filtered output from the median filter is then fed to the Weiner filter. This filter, in turn, smoothens and restores the required data of the chest pictures. This output is then fed to the image improvement filters say top hat and bot hat filters. Even once the background of the image and also the target color remains identical, the morphological filter analyses the same and identifies them as separate values even our eyes cannot determine. The output is then fed for segmentation. Here, marker-based watershed segmentation is used to avoid the over segmentation from distance transform watershed segmentation. The input image is then fed for image normalization, which reduces the after effect due to poor contrast or glare. Then the image is fed for gamma correction, which is mainly used for luminance correction. $\mathrm{K}$ means clustering is also employed. The combination of water marked watershed algorithm and the outputs followed by the $\mathrm{k}$ means yields an image segmentation method which got finest recall and precision value. The Flow chart illustration depicted below give the details of the segmentation. 


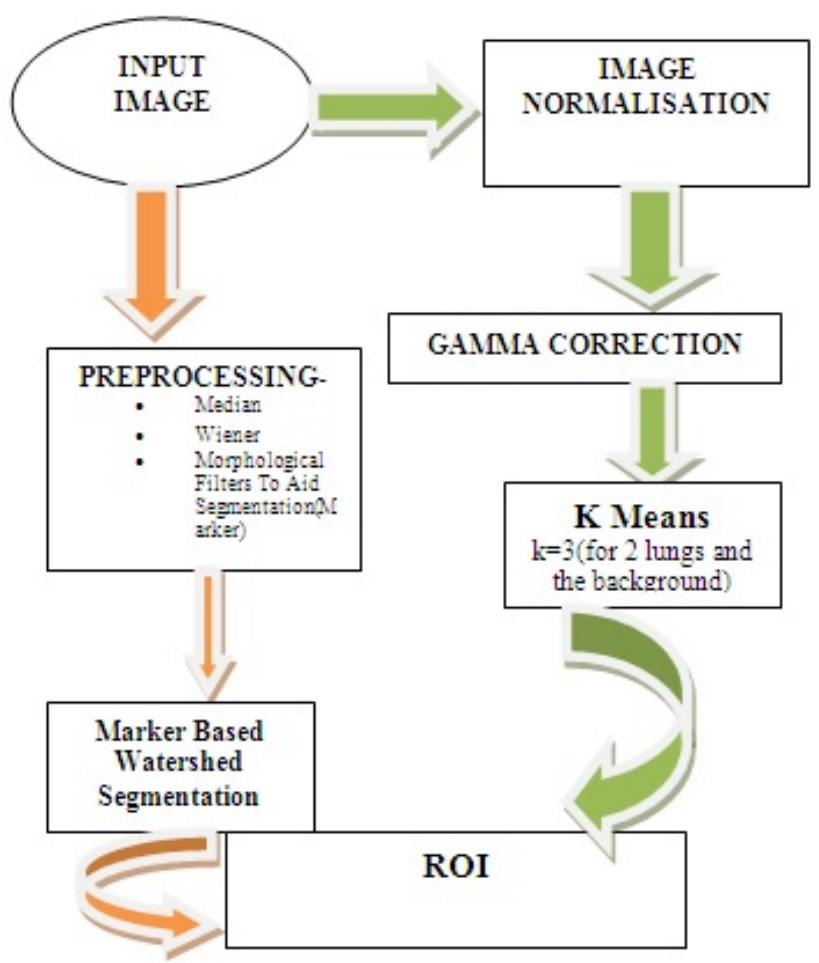

Graphic 1. Flow Chart.

Source: own elaboration.

\section{RESULTS}

\subsection{PERFORMANCE PARAMETERS FOR SEGMENTATION ANALYSIS}

\subsubsection{PRECISION}

In the chest x-ray images, precision is determined by the fraction of relevant elements (pixels) from the retrieved elements of the lung image. It is defined as:

$\mathrm{PR}=\mathrm{T}_{\mathrm{PO}} \div\left(\mathrm{T}_{\mathrm{PO}}+\mathrm{F}_{\mathrm{PO}}\right)$

PR-Precision

$\mathrm{T}_{\mathrm{PO}}$-True Positive

$\mathrm{F}_{\mathrm{PO}}$-False Positive 


\subsubsection{RECALL}

In the $\mathrm{X}$-ray chest image, the recall is the fraction of relevant X-ray pixel elements of the chest image that is been retrieved from the over the total amount of relevant pixel elements in the X-ray chest images. It is defined as:

$\mathrm{R}_{\mathrm{e}}=-\mathrm{T}_{\mathrm{PO}} \div\left(\mathrm{T}_{\mathrm{PO}}+\mathrm{F}_{\mathrm{NE}}\right)$

Re-Recall

$\mathrm{T}_{\mathrm{PO}}$-True Positive

$\mathrm{F}_{\mathrm{NE}}$-False Negative

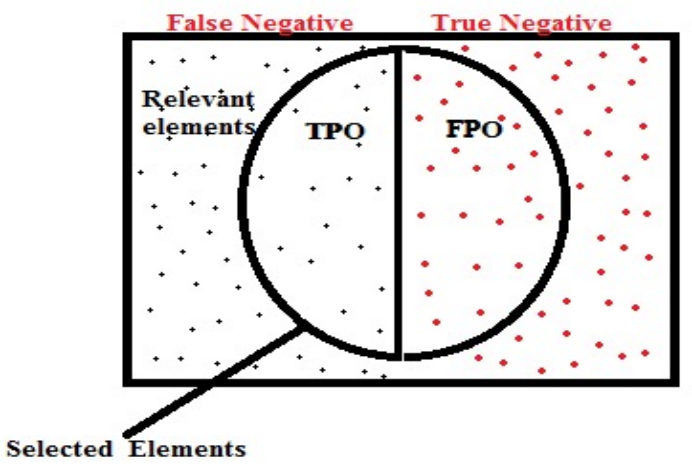

Figure 7. Details about precision and recall.

Source: own elaboration.

The graphical representation of both precision and recall values of various segmentation methods are discussed below. 


\subsubsection{FOR OTSU}

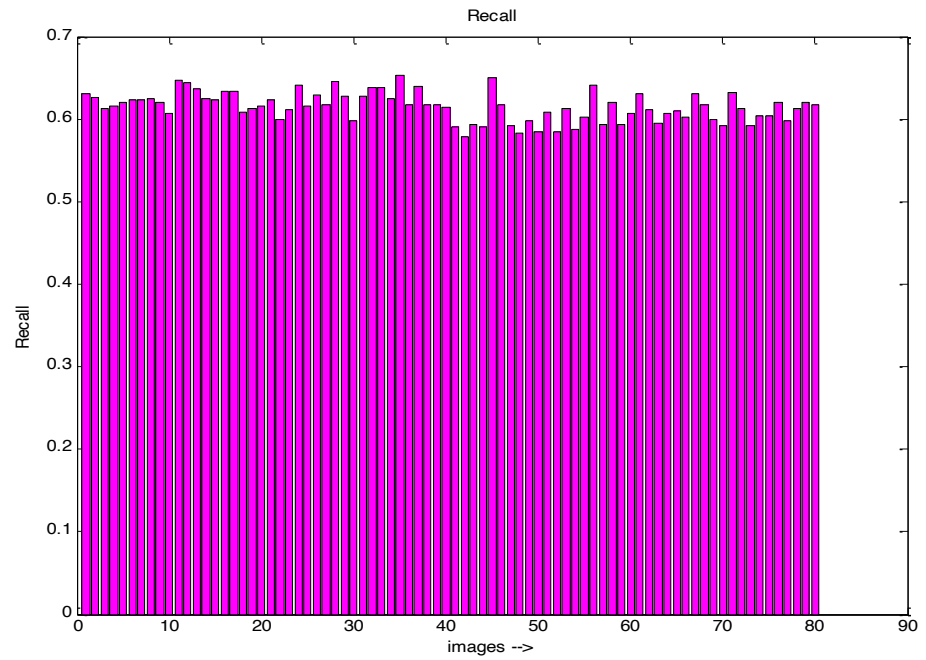

Figure 8. a) Recall values for Otsu segmentation for 80 chest images.

Source: own elaboration.

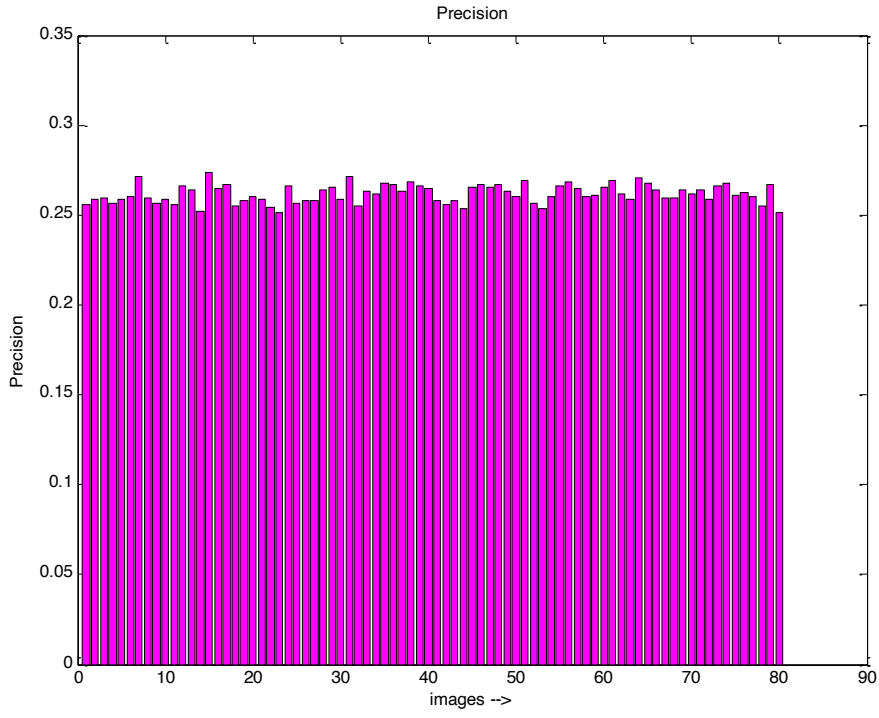

Figure 8. b) Precision for Otsu Segmentation for 80 chest images.

Source: own elaboration. 


\subsubsection{FOR WATERSHED SEGMENTATION}

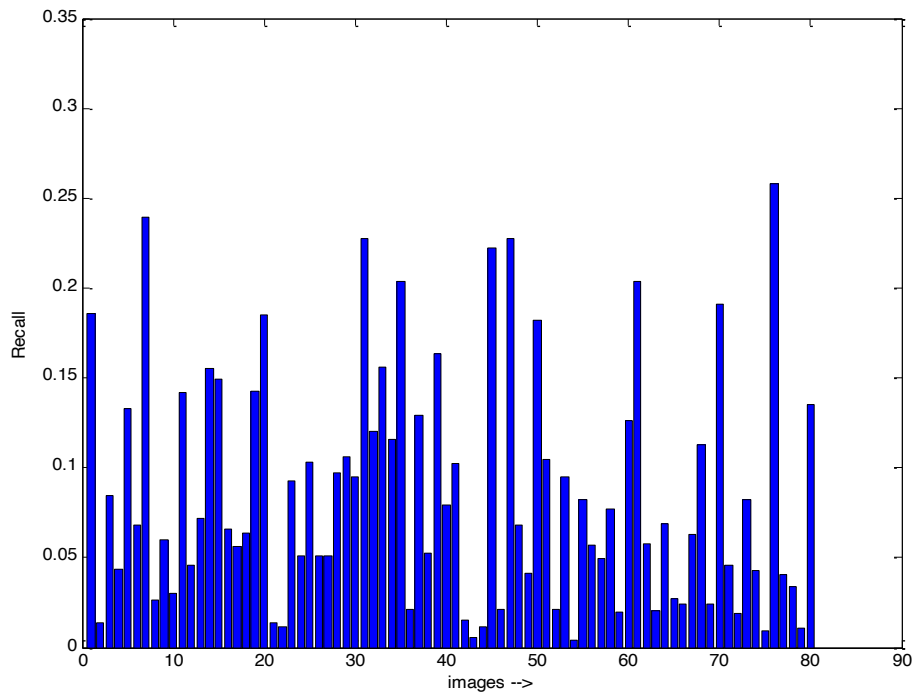

Figure 9. a) Recall for Watershed Segmentation for 80 chest images.

Source: own elaboration.

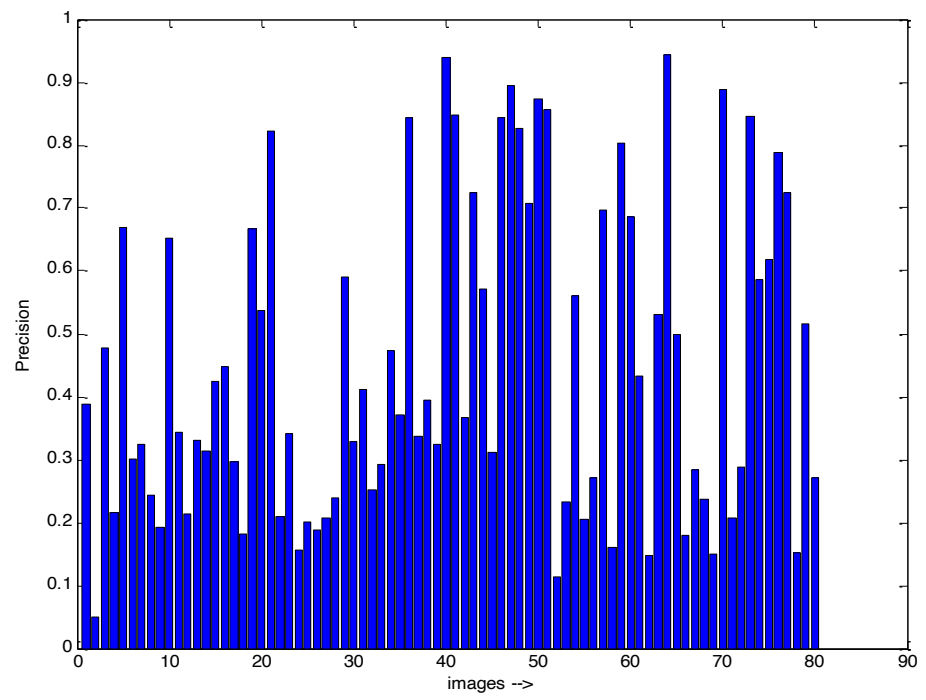

Figure 9. b) Precision for Watershed Segmentation for 80 chest images.

Source: own elaboration. 


\subsubsection{FOR MARKER-BASED WATERSHED SEGMENTATION}

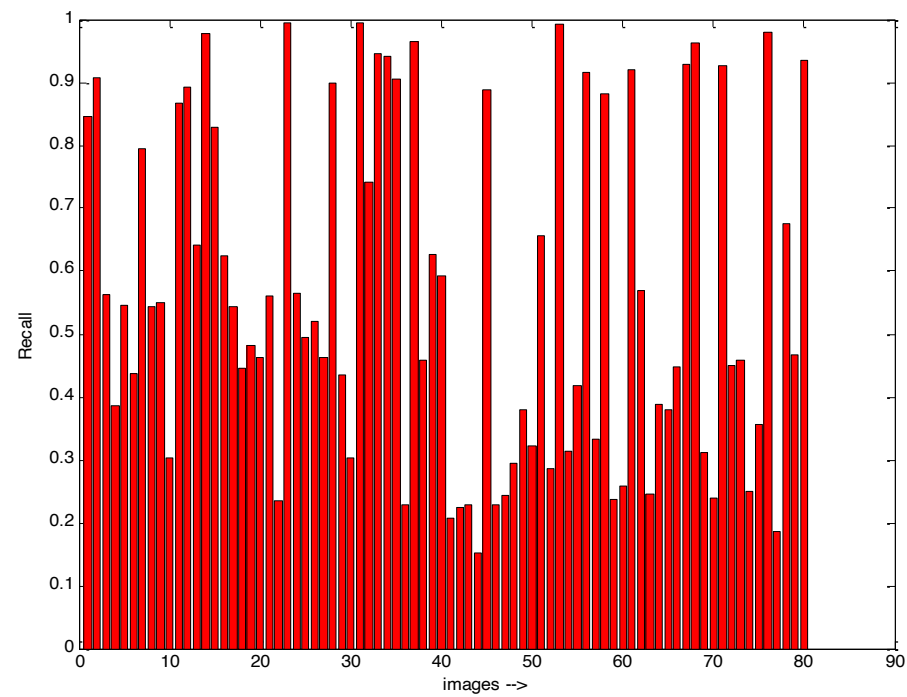

Figure 10. a) Recall for Marker-based Watershed Segmentation for 80 chest images.

Source: own elaboration.

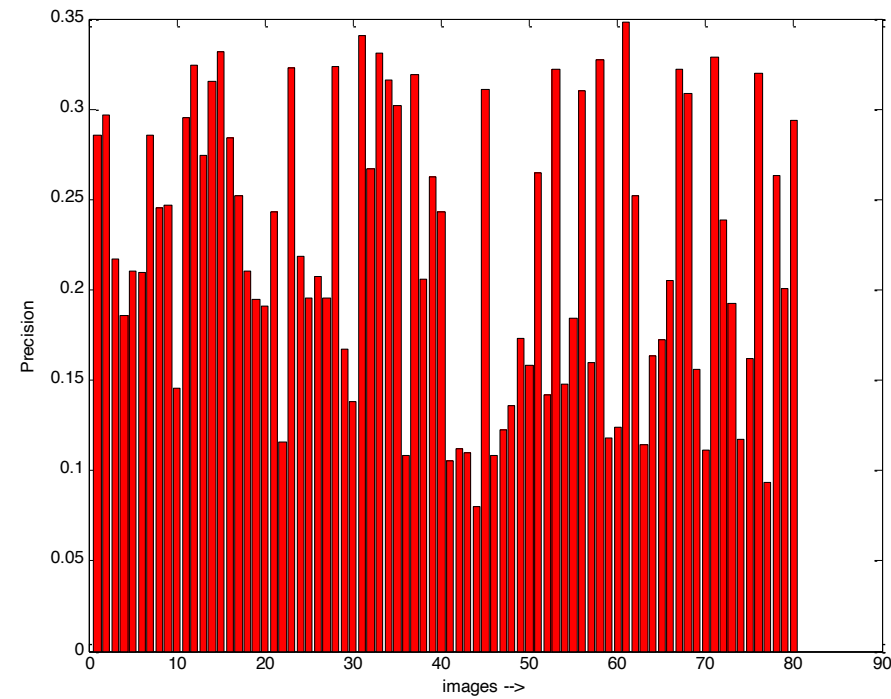

Figure 10. b) Precision for Marker-based Watershed Segmentation for 80 chest images. Source: own elaboration. 


\subsubsection{COMPARISON BETWEEN VARIOUS SEGMENTATION METHODS}

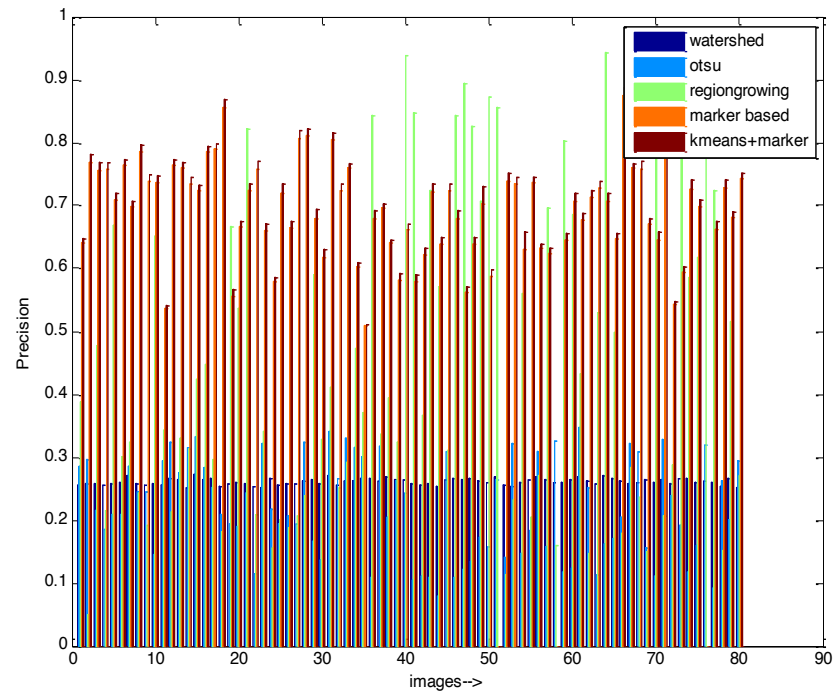

Figure 11. a) Precision Value comparison for watershed segmentation, Otsu, region growing, $\mathrm{k}$ means merged marker-based watershed segmentation for 80 chest X-ray images.

Source: own elaboration.

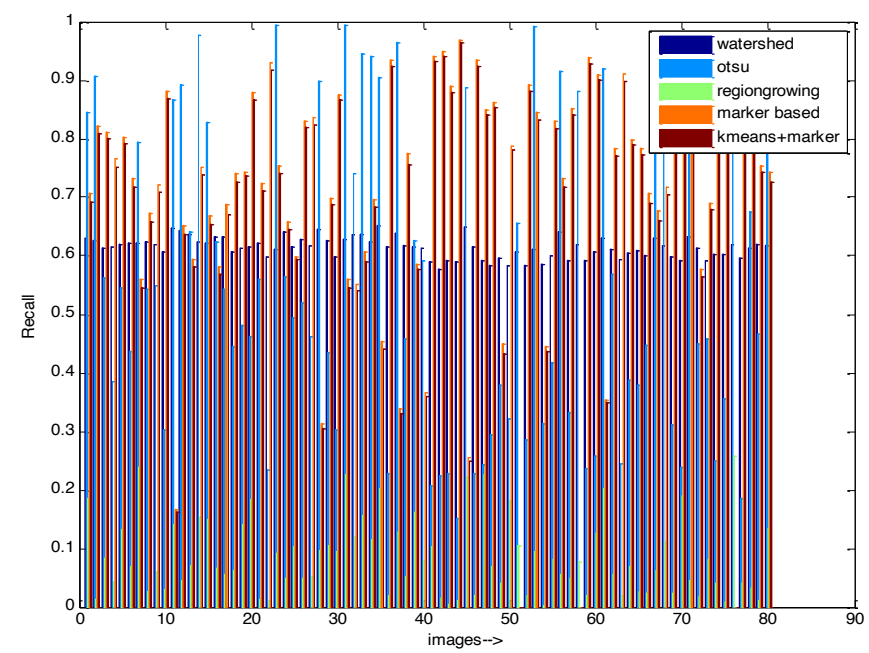

Figure 11. b) Recall Value comparison for watershed segmentation, Otsu, region growing, $\mathrm{k}$ means merged marker-based watershed segmentation for 80 chest X-ray images.

Source: own elaboration. 


\section{CONCLUSIONS}

Our paper gives a novelty approach of merging the segmentation methods for achieving a perfect ROI for getting better results for the precision and recall factors. Our approach is a new technique which merges two outputs of segmentation parts and accurately fixes the ROI. The input image is preprocessed, then fed for marker-based watershed segmentation. Meanwhile, the same input X-ray image is normalized in the other section, due to poor contrast or glare, then gamma correction is performed for the luminance part why because depending on the value of the gamma factor, the foreground and background visibility is made clearer. By increasing the value of gamma clear contrast between the backgrounds are behold in the x-ray image with mote clarity. Then k clusters are formed from the $\mathrm{n}$ neighboring elements. The output from this section is merged with the marker-based watershed segmentation and gets the correct ROI. Thus, new merged method is adapted for segmentation whose value is found to be great for the precision and recall value for around 80 images which is been shown in the graphs. This combination knocks out all the other segmentation methods so far discussed.

\section{REFERENCES}

Betsy, A., \& Nizar, B. P. K. (2017). Lung Tuberculosis Detection Using X-Ray Images. International fournal of Applied Engineering Research, 12(24), 15196-15201. https://www. ripublication.com/ijaer17/ijaerv12n24_175.pdf

Ghen, S.-D., \& Ramli, A. R. (2003). Contrast enhancement using recursive mean-separate histogram equalization for scalable brightness preservation. IEEE Transactions on Consumer Electronics, 49, 1301-1309. https://doi.org/10.1109/TCE.2003.1261233

Deivalakshmi, S., Saha, A., \& Pandeeswari, R. (2017). Raised Cosine Adaptive Gamma Correction for Efficient Image and Video Contrast Enhancement. In TENCON 2017 2017 IEEE Region 10 Conference. https:/ / doi.org/10.1109/tencon.2017.8228256

Furutani, K., Hirano, Y., \& Kido, S. (2019). Segmentation of lung region from chest x-ray images using U-net. In 2019 Foint International Workshop on Advanced Image 
Technology (IWAIT) and International Forum on Medical Imaging in Asia (IFMIA). https:/ / doi.org/10.1117/12.2521594

Guendel, S., Ghesu, F. G., Grbic, S., Gibson, E., Georgescu, B., Maier, A., \& Comaniciu, D. (2019). Multi-task Learning for Chest X-ray Abnormality Classification on Noisy Labels. Computer Vision and Pattern Recognition. https://arxiv. $\mathrm{org} / \mathrm{abs} / 1905.06362$

Hoffman, R. A., Kothari, S., \& Wang, M. D. (2014). Comparison of normalization algorithms for cross-batch color segmentation of histopathological images. In 2014 36th Annual International Conference of the IEEE Engineering in Medicine and Biology Society. https://doi.org/10.1109/embc.2014.6943562

Jeevitha, D., \& Rajasekaran, J. (2015). Histogram based tuberculosis analysis with parallel pixel processing. Fournal of Recent Research in Engineering and Technology, 2, 2349 -2260. http://www.jrret.com/archives/2015/paper/jun15/J61511.pdf

Jeyavathana, R. B., Balasubramanian, R., \& Pandian, A. (2017). An Efficient Feature Extraction Method for Tuberculosis detection using Chest Radiographs. International Journal of Applied Environmental Sciences, 12(2), 227-240. https://www.ripublication. com/ijaes17/ijaesv12n2_02.pdf

Kamra, P., Vishraj, R., \& Gupta, S. (2015). Performance comparison of image segmentation techniques for lung nodule detection in CT images. In 2015 International Conference on Signal Processing, Computing and Control (ISPCC). https://doi.org/10.1109/ ISPCG.2015.7375045

Karargyris, A., Antani, S., \& Thoma, G. (2011). Segmenting anatomy in chest x-rays for tuberculosis screening. In 2011 Annual International Conference of the IEEE Engineering in Medicine and Biology Society. https://doi.org/10.1109/IEMBS.2011.6091917

Kasu, N. R., \& Saravanan, C. (2019). Segmentation on Chest Radiographs Using Otsu's and K-Means Clustering Methods. In 2018 International Conference on Inventive Research in Computing Applications (ICIRCA). https:/ / doi.org/10.1109/ICIRCA.2018.8597371 
Kiran, M., Ahmed, I., Khan, N., \& Reddy, A. G. (2019). Chest X-ray segmentation using Sauvola thresholding and Gaussian derivatives responses. Fournal of Ambient Intelligence and Humanized Computing, 10, 4179-4195. https://doi.org/10.1007/ s12652-019-01281-7

Kumar, S. N., Fred A. L., Muthukumar, S., Kumar, H., A., \& Varghese, P, S. (2018). A Voyage On Medical Image Segmentation Algorithms. Biomedical Research, 29, 7587. https://doi.org/10.4066/biomedicalresearch.29-16-1785

Lu, S., Wang, S., \& Zhang, Y. (2017). A note on the marker-based watershed method for X-ray image segmentation. Computer Methods and Programs in Biomedicine, 141, 1-128. https://doi.org/10.1016/j.cmpb.2017.01.014

Manisha, R. K., \& Palanisamy, K. S. (2016). Computer-aided diagnosis of tuberculosis using chest radiographs. Discovery, 52(245), 1012-1019. http:/ /www. discoveryjournals. org/discovery/current_issue/v52/n245/A9.pdf

Poornimadevi, G. S., \& Sulochana, H. (2016). Automatic Detection Of Pulmonary Tuberculosis Using Image Processing Techniques. In 2016 International Conference on Wireless Communications, Signal Processing and Networking (WiSPNET). https://doi. org/10.1109/WiSPNET.2016.7566243

Quadeer, M. A., Naaz, S., \& Zerdi, N. (2017). Image Segmentation And Classification Model For Detection Of Tuberculosis. International Journal of Emerging Technology in Computer Science \& Electronics (IfETCSE), 24(6).

Raviglione, M., \& Sulis, G. (2016). Tuberculosis 2015: Burden, Challenges and Strategy for Control and Elimination. Infectious Disease Reports, 8(2), 6570. https://doi. org/10.4081/idr.2016.6570

Surya, S. J., Lakshmanan, S., \& Stalin, A. (2017). Automatic Tuberculosis Detection Using Chest Radiographs Using Its Features Abnormality Analysis. Fournal of Recent Research in Engineering and Technology, 4(9). https://www.researchgate.net/ publication/343793401_AUTOMATIC_TUBERGULOSIS_DETEGTION_ 
USING_CHEST_RADIOGRAPHS_USING_ITS_FEATURES _ ABNORMALITY_ANALYSIS

Vidya, M. S., Manikanda, K. V., Anirudh, G., Srinivasa, R. K., \& Vijayananda, J. (2019). Local and global transformations to improve learning of medical images applied to chest radiographs. In SPIE Medical Imaging. https://doi. org/10.1117/12.2512717

Vital, D. A., Sais, B. T., \& Moraes, M. C. (2019). Automatic Pulmonary Segmentation in Chest Radiography, Using Wavelet, Morphology and Active Contours. In CostaFelix, R., Machado, J., \& Alvarenga, A. (eds.) XXVI Brazilian Congress on Biomedical Engineering. IFMBE Proceedings, vol 70/2. Springer, Singapore. https://doi. org/10.1007/978-981-13-2517-5_12

Zhang, X., Jia, F., Luo, S., Liu, G., \& Hu, Q. (2013). A marker-based watershed method for X-ray image segmentation. Computer Methods and Programs in Biomedicine, 113(3), 894-903. https://doi.org/10.1016/j.cmpb.2013.12.025 
